\title{
Effect of rasagiline on the molecular composition of the excitatory postsynaptic density
}

\author{
Fabrizio Gardoni ${ }^{\text {a }}$, Elisa Zianni ${ }^{a}$, Anna Eramo ${ }^{c}$, Pier Luigi Canonico ${ }^{\text {b }}$, Monica Di Luca a,* \\ a Department of Pharmacological Sciences University of Milan, Via Balzaretti 9, 20133 Milan, Italy \\ b DiSCAFF and DFB Center, Università del Piemonte Orientale, Novara, Italy

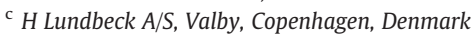

\section{A R T I C L E I N F O}

\section{Article history:}

Received 28 February 2011

Received in revised form 31 August 2011

Accepted 7 September 2011

Available online 21 September 2011

\section{Keywords:}

Rasagiline

NMDA receptor

Postsynaptic density

Neuroprotection

Rat

Parkinson's disease

\begin{abstract}
A B S T R A C T
In the last decade, several neuroprotective therapies have been proposed for Parkinson's disease and rasagiline was indicated as one of the most promising candidates by preclinical studies. The drug has already been tested in phase III clinical studies (the ADAGIO study). The mechanism underlying rasagiline-dependent neuroprotection is complex and almost unknown. Here, we show that rasagiline is involved in the regulation of the molecular composition of the postsynaptic density of glutamatergic synapses. In hippocampus as well as in striatum, rasagiline induces a significant reduction of synaptic levels of NR2A-containing NMDA receptors and in hippocampal slices it also significantly decreases synaptic levels of GluR1-containing AMPA receptors. This capability of rasagiline to modulate ionotropic glutamate receptors composition at synaptic sites strengthens the rationale for its clinical use to slow the progression of Parkinson's disease.
\end{abstract}

(c) 2011 Elsevier B.V. All rights reserved.

\section{Introduction}

Despite extensive studies performed both in vivo on animal models and ex vivo on postmortem brains from patients, Parkinson's disease etiology is still largely unknown (Lees et al., 2009). Nonetheless, neurotoxic events as mitochondrial dysfunction, increased oxidative stress, excitotoxicity and inflammation are thought to have a role in the neurodegenerative process (Schapira, 2008).

Agents, able to target these events, can become neuroprotective and/or disease modifying therapies. In this frame, rasagiline, an inhibitor of monoamine oxidase type B (MAO-B), is one of the most promising candidates (Chen et al., 2007). Rasagiline exerts its neuroprotective activity against neurotoxins both in cell cultures and in animal models of Parkinson's disease and this protection is dependent on the intervention of 'intrinsic' mitochondrial apoptotic cascade and on the induction of prosurvival antiapoptotic Bcl-2 and of other neurotrophic factors (Bar-Am et al., 2005; Naoi and Maruyama, 2009; Weinreb et al., 2009a,b). Interestingly, comparison of structure-activity assays among rasagiline and other classical MAO$\mathrm{B}$ inhibitors, i.e. selegiline, demonstrated that, in all compounds, the

\footnotetext{
* Corresponding author. Tel.: + 390250318374 ; fax: + 390250318284. E-mail addresses: fabrizio.gardoni@unimi.it (F. Gardoni), elisa.zianni@unimi.it (E. Zianni), AERA@Lundbeck.com (A. Eramo), canonico@pharm.unipmn.it (P.L. Canonico), monica.diluca@unimi.it (M. Di Luca).
}

N-propargyl moiety is responsible for neuronal survival via a similar neuroprotective mechanism (Bar-Am et al., 2004, 2005). However, several preclinical studies suggested a higher neuroprotective potency of rasagiline compared to selegiline, which is probably related to their different metabolites (Chen and Ly, 2006; Chen et al., 2007).

Rasagiline efficacy for Parkinson's disease treatment was further confirmed by clinical trials, whose results led to its authorization for use in early and advanced Parkinson's disease stages (Weinreb et al., 2010). The symptomatic benefits induced by rasagiline were mainly attributed to MAO-B inhibition but other mechanisms seem to be involved (Naoi and Maruyama, 2009; Weinreb et al., 2010): rasagiline neuroprotective activity can be observed at concentrations below MAO-B inhibition threshold, suggesting that it cannot be completely ascribed to MAO-B inhibition (Weinreb et al., 2010). Even novel delayed start clinical studies, including the large phase III ADAGIO trial (Olanow et al., 2008, 2009), suggested that rasagiline may have an effect in slowing Parkinson's disease progression, which is considered additional - if not independent - to MAO-B inhibition. Interestingly, MAO-B inhibitors have been shown to partially protect neurons against overactivation of NMDA receptors without interfering with their physiological function (Niittykoski et al., 2003). This is intriguing since NMDA receptor is altered in experimental parkinsonism (Dunah and Standaert, 2001; Paillé et al., 2010), during development of L-DOPA induced dyskinesia (Gardoni et al., 2006) and in patients (Calon et al., 2003). In addition, synaptic localization of NMDA receptor subunits, namely NR2A and NR2B, and their functional interactions with scaffolding elements of the PSD-MAGUK 
protein family have been shown to be crucial to the pathogenesis of Parkinson's disease and to the development of L-DOPA induced dyskinesia (Gardoni et al., 2006; Picconi et al., 2004). In a rat model of early Parkinson's disease, normalization of the aberrant synaptic localization of NR2A subunits rescued the motor symptoms (Paillé et al., 2010).

Here we show that treatment of corticostriatal slices with rasagiline specifically reduces NR2A subunit localization in the postsynaptic compartment without affecting the synaptic localization of any other tested protein. Similarly, treatment of hippocampal slices with rasagiline reduces NMDA receptor NR2A subunit but also affects AMPA receptor GluR1 subunit levels in the postsynaptic compartment.

\section{Material and methods}

\subsection{Preparation of acute slices}

Acute hippocampal and corticostriatal slices were prepared from adult rats as previously described (Gardoni et al., 2001). All experiments were approved by institutional ethics committee. Animal handling and surgical procedures were carried out with care to minimize discomfort and pain to treated animals in accordance with ethical regulations and guidelines of the European Communities Council (Directive of November 24, 1986, 86/609/EEC). Briefly, brains were removed and placed into chilled $\left(4^{\circ} \mathrm{C}\right)$ oxygenated Krebs' buffer. After removal of meninges, hippocampal slices $(450 \mu \mathrm{m})$ were prepared quickly using a Mcllwain tissue chopper and placed in custom-made chambers equilibrated continuously with $\mathrm{O}_{2} 95 \%-\mathrm{CO}_{2} 5 \%(\mathrm{v} / \mathrm{v})$. Corticostriatal slices have been obtained similarly by using a vibratome $(450 \mu \mathrm{m})$.

Slices were then equilibrated $\left(\mathrm{O}_{2} 95 \%-\mathrm{CO}_{2} 5 \%\right)$ at room temperature for $30 \mathrm{~min}$. After the equilibration time, slices were incubated with rasagiline ( $5 \mathrm{~min}, 30 \mathrm{~min}, 2 \mathrm{~h} ; 0.1-1-10 \mu \mathrm{M}$ ) or with vehicle alone. After incubation, slices were quickly transferred into the homogenization chamber. In experiments performed in corticostriatal slices, before homogenization striatum were carefully separated from the cortex and subsequently homogenized.

\subsection{Subcellular fractionation}

Triton-Insoluble postsynaptic Fraction (TIF) was purified from blind samples of control and rasagiline treated slices using a previously validated biochemical fractionating method (Gardoni et al., 2006). Briefly, slices were homogenized in ice-cold sucrose $0.32 \mathrm{M}$ containing Hepes $1 \mathrm{mM}, \mathrm{MgCl}_{2} 1 \mathrm{mM}$, EDTA $1 \mathrm{mM}, \mathrm{NaHCO}_{3} 1 \mathrm{mM}$, PMSF $0.1 \mathrm{mM}$, at pH 7.4 in presence of a complete set of protease inhibitors (Complete ${ }^{\mathrm{TM}}$, Roche Diagnostics, Basel, Switzerland) and phosphatase inhibitors (Sigma-Aldrich). The homogenized tissue was centrifuged at $1000 \times g$ for $10 \mathrm{~min}$. The resulting supernatant (S1) was centrifuged at $13,000 \times \mathrm{g}$ for $15 \mathrm{~min}$ to obtain a crude membrane fraction (P2 fraction). The pellet was re-suspended in Hepes $1 \mathrm{mM}+$ Complete $^{\mathrm{TM}}$ in a glass-glass potter and centrifuged at $100,000 \times \mathrm{g}$ for $1 \mathrm{~h}$. The pellet (P3) was resuspended in buffer containing $75 \mathrm{mM} \mathrm{KCl}$ and $1 \%$ Triton-X 100 and centrifuged at $100,000 \times g$ for $1 \mathrm{~h}$. The supernatant was stored and referred as Triton soluble fraction (S4, TSF). The final pellet (P4) was homogenized in a glass-glass potter in $20 \mathrm{mM}$ Hepes. Then, an equal volume of glycerol was added and this fraction, referred to as Triton insoluble fraction (TIF), was stored at $-80^{\circ} \mathrm{C}$ until processing. TIF fraction was used instead of the classical postsynaptic density (PSD) because of the limited amount of starting material. Similar protein yield $(\sim 100 \mu \mathrm{g})$ was obtained in TIF purified from hippocampal and striatal slices for both experimental groups. Protein composition of this preparation was tested for absence of presynaptic synaptic vesicle marker synaptophysin (Gardoni et al., 2001) and enrichment in the PSD proteins (Gardoni et al., 2006).

\subsection{Western blot analysis}

Western blot analysis was performed as described before with minor modifications (Gardoni et al., 2006). Samples (10 $\mu \mathrm{g}$ ) were applied to SDS-PAGE and electroblotted. After blocking non specific protein interactions with $5 \%$ albumin in Tris-buffered saline (TBS), the nitrocellulose membranes were incubated for $2 \mathrm{~h}$ at room temperature with the following primary antibodies: NR2A (1:1000, Zymed, San Francisco, CA, USA), NR2B (1:1000, Zymed), GluR1 (1:1500, Millipore, USA), PSD-95 (1:2000, Affinity BioReagents, Golden, CO, USA), SAP97 (1:1000, Affinity BioReagents), SAP102 (1:2000, Neuromab, Davis, CA, USA), $\alpha$ CaMKII (1:3000; Millipore, USA), $\alpha$-Tubulin (1:5000; Sigma) in $3 \%$ albumin in TBS. After extensive rinsing in TBS/0.1\% Tween 20, the nitrocellulose papers were incubated with horseradish peroxidaseconjugated secondary antibodies. Finally, the antigen-antibody complex was revealed by enhanced chemiluminescence (ECL, GE Healthcare, Little Chalfont, UK).

\subsection{Quantification and statistical analysis}

Quantification of Western blot analysis was performed by means of computer-assisted imaging (Quantity-One ${ }^{\circledR}$, BioRad) after normalization on tubulin levels and values were expressed as mean \pm S.E.M. For each homogenate and TIF preparation three independent experiments were run. Student's $t$ test was used to compare results from control and rasagiline-treated slices.

\section{Results}

\subsection{Effect of rasagiline on molecular composition of glutamatergic} synapses in striatum

In a first set of experiments, acute corticostriatal slices were treated for $2 \mathrm{~h}$ with rasagiline $(10 \mu \mathrm{M})$. After treatment, slices were lysed and the triton insoluble postsynaptic fraction (TIF) was purified. TIF is a highly purified postsynaptic fraction (Gardoni et al., 2001, 2006), the ideal compartment to study the role of rasagiline in modulation of the molecular composition of postsynaptic compartment. The effect of rasagiline treatment was tested on ionotropic glutamate receptor subunits as well as on the main PSD-structural elements by western blot analysis. In particular, western blot was performed for NR2A and NR2B subunits of NMDA receptor, for GluR1 and GluR2 subunits of AMPA receptor (Fig. 1, upper panels), for all main PSDMAGUK members (PSD-95, SAP97 and SAP102) and for $\alpha$ CaMKII (Fig. 1, lower panels).

As shown in Fig. 1, levels of NMDA receptor subunit, NR2B, of GluR1 and GluR2 subunits of AMPA receptor, of PSD-95, SAP97 and SAP102, members of PSD-MAGUK protein family, and of $\alpha$ CaMKII were not altered in striatal TIF obtained from rasagiline-treated corticostriatal slices $(2 \mathrm{~h}, 10 \mu \mathrm{M})$ compared to control. Interestingly, treatment with rasagiline specifically reduced synaptic levels of NMDA receptor subunit, NR2A $(-43.2 \pm 15.1, \mathrm{P}<0.05 ; \mathrm{n}=5)$.

\subsection{Effect of rasagiline on molecular composition of glutamatergic synapse in hippocampus}

The above described western blot experiments were performed also on acute hippocampal slices after treatment with rasagiline $(2 \mathrm{~h}, 10 \mu \mathrm{M})$. As shown in Fig. 2, levels of NMDA receptor subunit, NR2B, of GluR2 subunit of AMPA receptor, of PSD-95, SAP97, SAP102 and of $\alpha$ CaMKII were not modified in TIF of rasagiline-treated hippocampal slices $(2 \mathrm{~h}, 10 \mu \mathrm{M})$ compared to control. Notably, in hippocampal slices treatment with rasagiline not only reduced synaptic levels of NMDA receptor subunit NR2A $(-22.1 \pm 6.5, \mathrm{P}<0.05 ; \mathrm{n}=5)$ but also significantly decreased levels of AMPA receptor subunit GluR1 ( $-40.9 \pm 8.8, \mathrm{P}<0.05 ; \mathrm{n}=5)$. 

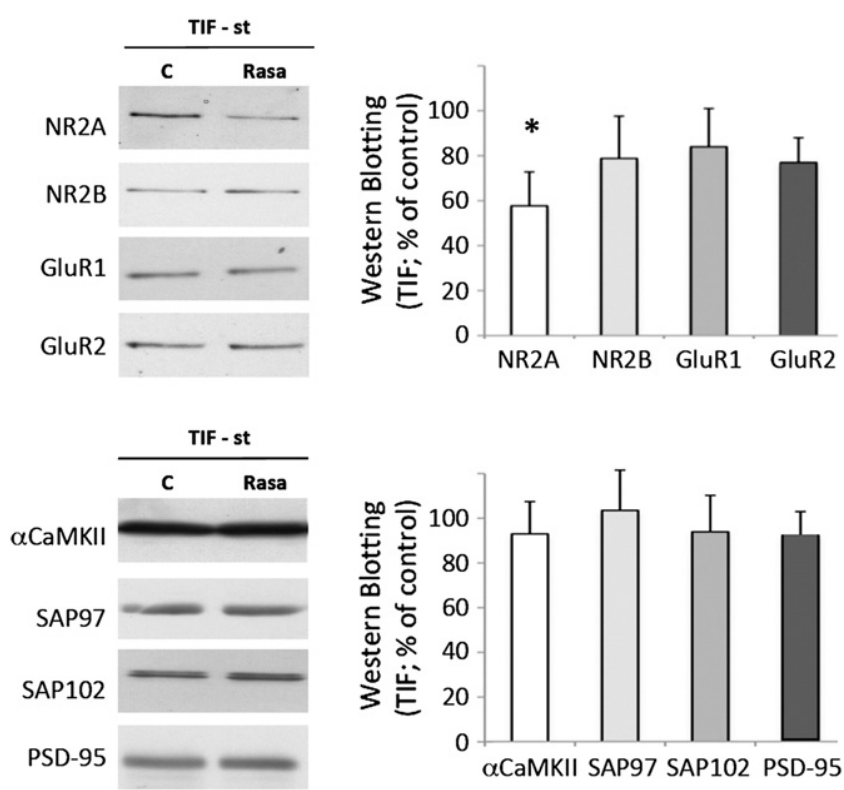

Fig. 1. Western blot analysis of TIF fraction obtained from control $(n=5)$ and rasagilinetreated $(\mathrm{n}=5 ; 10 \mu \mathrm{M}, 2 \mathrm{~h}$ ) acute corticostriatal slices. The same amount of proteins was loaded in each lane. Rasagiline treatment leads to a decreased localization of NR2A subunit of NMDA receptor in the TIF.

In parallel experiments, western blot analyses were performed for the same proteins in homogenate fractions from control and rasagilinetreated corticostriatal (Fig. 3) and hippocampal (Fig. 4) slices. No differences in any tested protein were detected nor in corticostriatal (Fig. 3) neither in hippocampal slices (Fig. 4), suggesting that the observed decrease of NR2A and GluR1 at synaptic levels was not consequent to alterations of protein expression in total homogenate but probably to modifications of trafficking/clustering at synaptic sites.
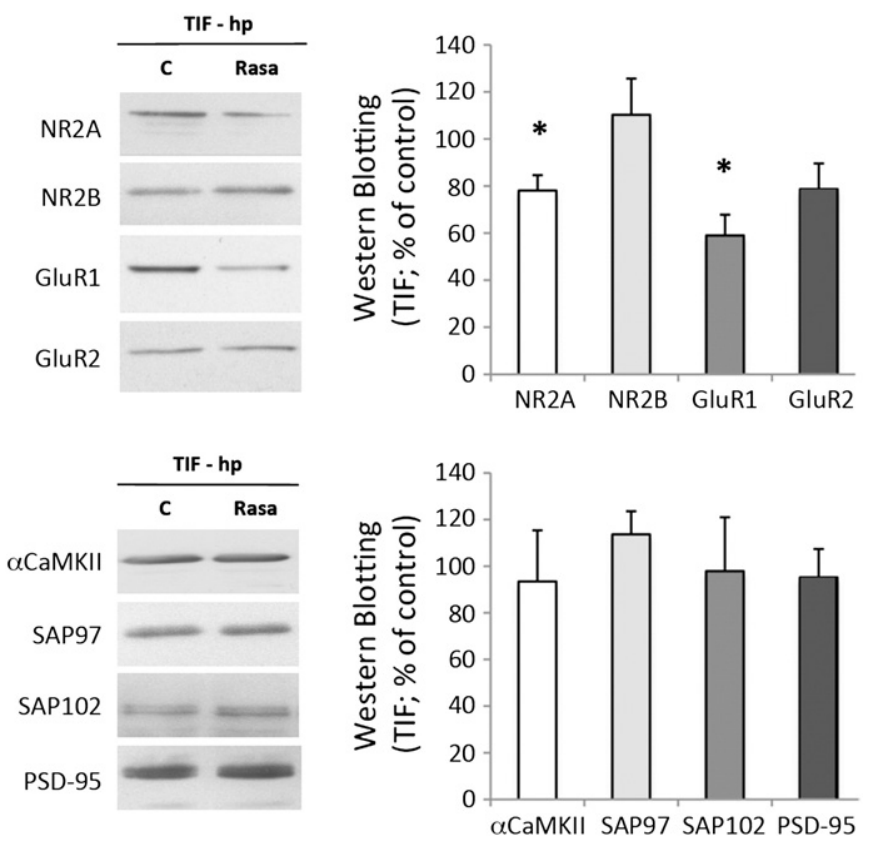

Fig. 2. Western blot analysis of TIF fraction obtained from control $(n=5)$ and rasagiline treated $(\mathrm{n}=5 ; 10 \mu \mathrm{M}, 2 \mathrm{~h}$ ) acute hippocampal slices. The same amount of proteins was loaded in each lane. Rasagiline treatment leads to a decreased localization of NR2A subunit of NMDA receptor and of GluR1 subunit of AMPA receptor in the TIF.
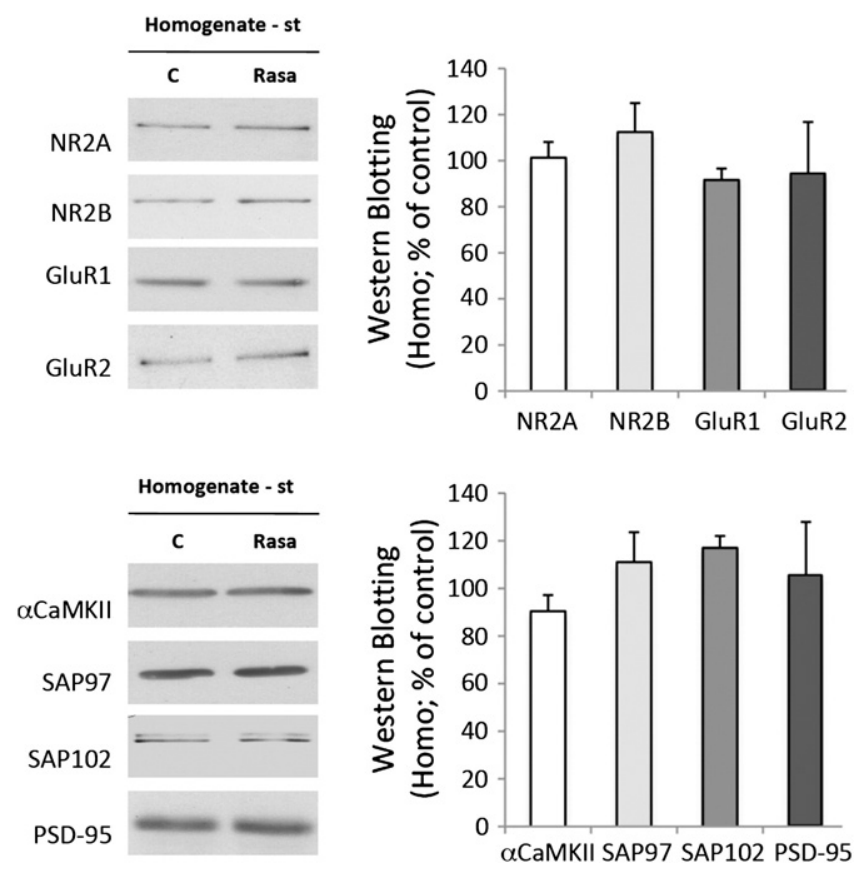

Fig. 3. Western blot analysis of homogenate fraction obtained from control $(n=5)$ and rasagiline-treated $(\mathrm{n}=5 ; 10 \mu \mathrm{M}, 2 \mathrm{~h}$ ) acute corticostriatal slices. The same amount of proteins was loaded in each lane. Rasagiline treatment does not affect the expression of any tested protein.

\subsection{Concentration-response curve of rasagiline effect on molecular composition of glutamatergic synapses}

In vitro studies indicated that the neuroprotective activity of rasagiline can be observed at concentrations below the MAO-B inhibition threshold (Weinreb et al., 2010), mainly between 0.1 and $10 \mu \mathrm{M}$
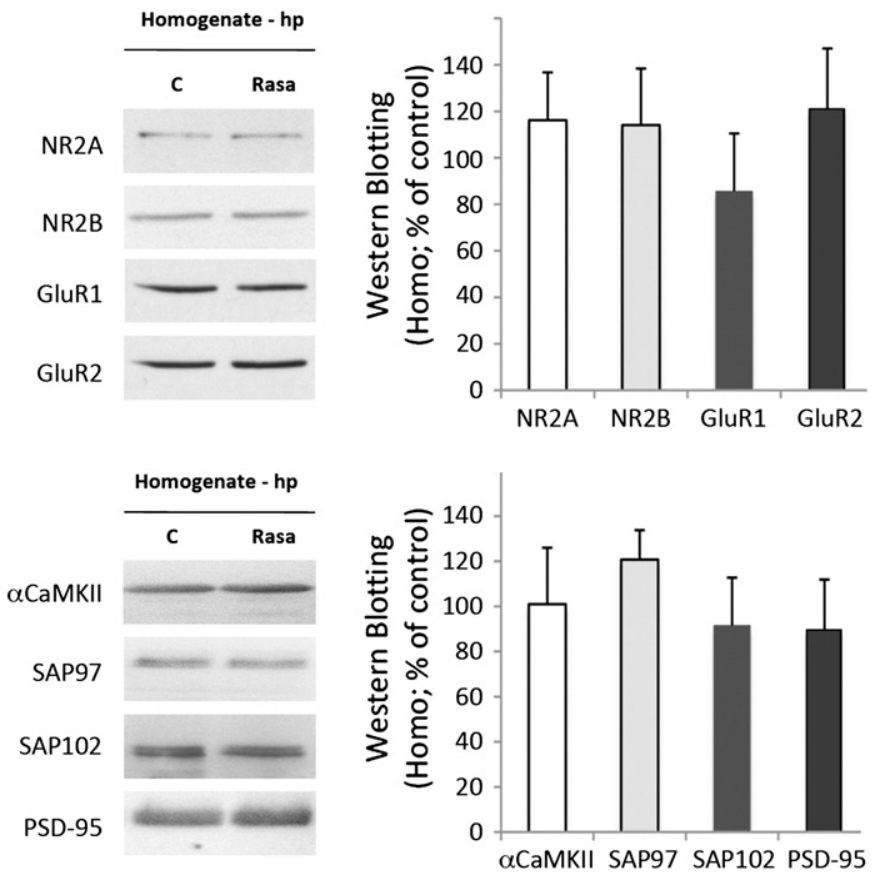

Fig 4. Western blot analysis of homogenate fraction obtained from control $(n=5)$ and rasagiline-treated $(\mathrm{n}=5 ; 10 \mu \mathrm{M}, 2 \mathrm{~h})$ acute hippocampal slices. The same amount of proteins was loaded in each lane. Rasagiline treatment does not affect the expression of any tested protein. 
(Bar-Am et al., 2005; Dimpfel and Hoffmann, 2011; Weinreb et al., 2007). On these bases, we treated acute corticostriatal and hippocampal slices with rasagiline 0.1 and $1 \mu \mathrm{M}$ for 2 hours. Treatment with rasagiline $1 \mu \mathrm{M}$ gave the same results as concentration of $10 \mu \mathrm{M}$ : NR2A synaptic levels were reduced in both corticostriatal $(-15.8 \pm 3.7 \%, \mathrm{P}<0.05 ; \mathrm{n}=5)$ and hippocampal slices $(-20.8 \pm 5.5 \%$, $\mathrm{P}<0.05 ; \mathrm{n}=5$ ) while GluR1 was significantly decreased just in hippocampus ( $-29.3 \pm 5.8 \%, P<0.05 ; n=5)$ (Fig. $5 \mathrm{~A}$ and $\mathrm{B}$ ). No effects were observed on synaptic composition after treatment with rasagiline $0.1 \mu \mathrm{M}$ for $2 \mathrm{~h}$ either in hippocampal or in corticostriatal slices (Fig. 5A and B).

\subsection{Time-course of rasagiline effects on molecular composition of glutamatergic synapses}

$1 \mu \mathrm{M}$ is the lowest rasagiline concentration able to induce a significant modification of the molecular composition of glutamatergic synapses. Accordingly, this concentration was used to study the time course of rasagiline effect on NR2A levels. In particular, we evaluated whether shorter treatments with rasagiline ( 5 and $30 \mathrm{~min}$ ) were sufficient to alter the molecular composition of glutamatergic synapses. Fig. 6 shows that 5 and 30 minute treatments of corticostriatal (Fig. 6A) or hippocampal (Fig. 6B) slices with rasagiline do not modify synaptic levels of AMPA or NMDA receptor subunits.

\section{Discussion}

In the last few years, several preclinical studies have shown that rasagiline has a broad neuroprotective activity in both cultured neuronal cells and animal models of neurodegenerative diseases (Weinreb et al., 2009a,b). Rasagiline-mediated neuroprotective mechanisms include suppression of the cell death cascade initiated by Bcl-2 family and by caspase-3, prevention of the decline in mitochondrial membrane potential as well as of nuclear translocation of glyceraldehyde-3-phosphate dehydrogenase (GAPDH) and of DNA fragmentation (Weinreb et al., 2009a,b). In addition, a recent study demonstrated that, in rat midbrain, rasagiline increases expression of various genes including neurotrophic factors, neuroactive ligand receptors, antioxidant and metabolic enzymes, while it downregulates genes associated with neurodegenerative diseases (Weinreb et al., 2009a,b).

Here we add further information to the mechanisms responsible for rasagiline-dependent neuroprotection, showing that rasagiline modifies the molecular composition of glutamatergic synapses.

Molecular composition and, consequently, structure of the postsynaptic compartment of excitatory synapses are intimately involved not only in the regulation of physiological processes, such as synaptic plasticity, but also in the dynamic response to different excitotoxic insults (Gardoni et al., 2009). Given that NMDA receptors mediate the rise in postsynaptic $\mathrm{Ca}^{2+}$, neuronal firing pattern and synaptic plasticity, the dynamic regulation of the number and composition of synaptic NMDA receptor is expected to have profound implications for neuronal activity and survival (Lau and Zukin, 2007).

In particular, our results indicate that rasagiline reduces synaptic levels of NR2A-containing NMDA receptors in both hippocampus and striatum. In addition, in hippocampal - but not in corticostriatal slices - rasagiline also decreases synaptic GluR1-containing AMPA receptors. These effects start at very low concentrations $(1 \mu \mathrm{M})$, in agreement with in vitro studies investigating rasagiline neuroprotective activity (Bar-Am et al., 2005; Weinreb et al., 2007). Moreover, time course experiments indicate that this rearrangement of glutamatergic synapses is not a fast event implying a prompt trafficking/ endocytosis of receptor subunits.

Our results showing a concomitant NR2A and GluR1 reduction in hippocampal slices treated with rasagiline confirm previous data demonstrating that, in mature hippocampal neurons, the surface expression of GluR1 subunit of AMPA receptor is supported by the presence of NR2A-containing NMDA receptors (Kim et al., 2005). Interestingly, here we show that this event does not take place in the striatum where a decrease of NR2A synaptic levels is not paralleled by a concomitant decrease of GluR1.

In striatal neurons, hyperfunction of NMDA receptors is suggested to contribute to parkinsonian symptoms and to treatment-induced motor complications, including L-DOPA-induced dyskinesia in Parkinson's disease (Nash and Brotchie, 2002; Verhagen Metman,
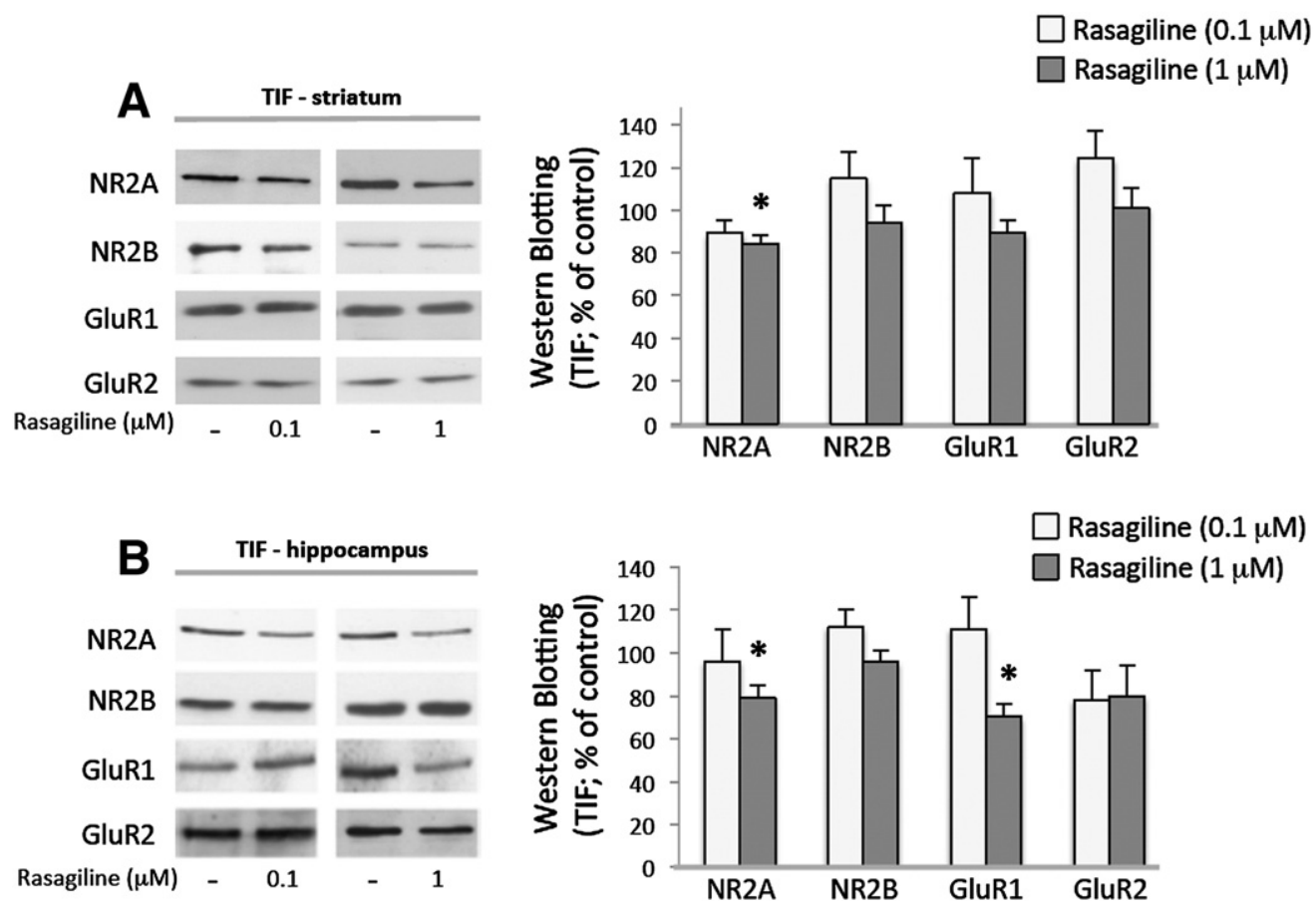

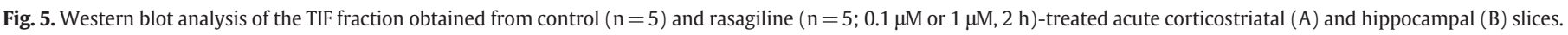
The same amount of proteins was loaded in each lane. 

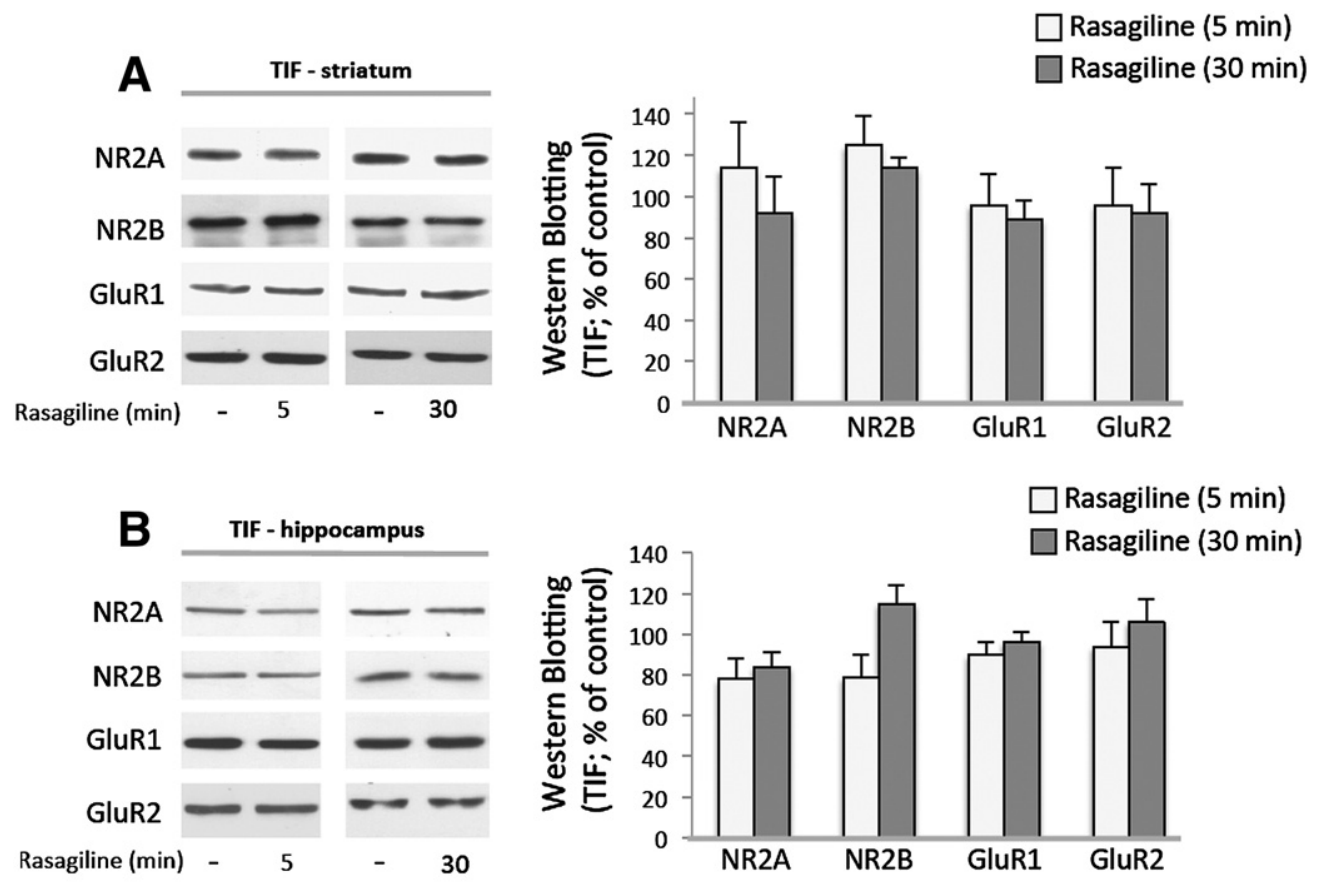

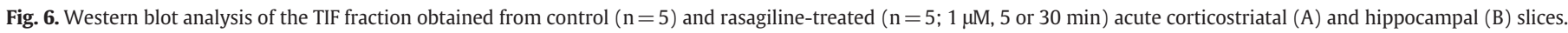
The same amount of proteins was loaded in each lane.

2002). In particular, subcellular redistribution of NR2A and NR2B subunits of NMDA receptor, leading to an increased NR2A/NR2B ratio at synaptic sites, is a key element in the complex modifications of glutamatergic synapses which occur both in experimental parkinsonism and in L-DOPA induced dyskinesia (Gardoni et al., 2006; Picconi et al., 2004). Normalization of NR2A subunit localization at synapses in a rat model of early Parkinson's disease is sufficient to improve motor behavior and to rescue corticostriatal synaptic plasticity (Paillé et al., 2010). Here we show that rasagiline can directly modulate NMDA receptor composition at synapse and, consequently, its function, by decreasing NR2A at synaptic sites. This is confirmed by a very recent report describing significant decreases of glutamate receptors-mediated signaling in hippocampus, following treatment with rasagiline at similar concentrations (Dimpfel and Hoffmann, 2011). Moreover, recent data reported a critical functional role for NR2Acontaining NMDA receptors - and a less crucial role for NR2B-containing NMDA receptors - in the depression of glutamatergic synaptic transmission and evoked dopamine release in striatum (Schotanus and Chergui, 2008; Schotanus et al., 2006). In this frame, rasagiline-dependent reduction of NR2A-containing NMDA receptor levels could unmask this NR2A-dependent effect and could modulate both glutamatergic and dopaminergic transmission at striatal level.

These novel effects of rasagiline on molecular composition of glutamatergic synapses in striatum and hippocampus are likely to occur independently from MAO-B inhibition, which was considered as the main cause of rasagiline beneficial effects on Parkinson's disease symptoms. Therefore, our observations suggest an additional mechanism for rasagiline disease-modifying action that could explain the positive results obtained by rasagiline in clinical trials for Parkinson's disease.

\section{Acknowledgments}

This work was partly supported by the European Community Contract 222918 (Restorative Plasticity at Corticostriatal Excitatory Synapses) FP7 Thematic Priority HEALTH (MDL). The authors are grateful to H Lundbeck A/S, Valby, Copenhagen, Denmark for its support to this work.

\section{References}

Bar-Am, O., Yogev-Falach, M., Amit, T., Sagi, Y., Youdim, M.B.H., 2004. Regulation of protein kinase $\mathrm{C}$ by the anti-Parkinson drug, MAO-B inhibitor, rasagiline and its derivatives, in vivo. J. Neurochem. 89, 1119-1125.

Bar-Am, O., Weinreb, O., Amit, T., Youdim, M.B., 2005. Regulation of Bcl-2 family proteins, neurotrophic factors, and APP processing in the neurorescue activity of propargylamine. FASEB J. 19, 1899-1901.

Calon, F., Rajput, A.H., Hornykiewicz, O., Bédard, P.J., Di Paolo, T., 2003. Levodopainduced motor complications are associated with alterations of glutamate receptors in Parkinson's disease. Neurobiol. Dis. 14, 404-416.

Chen, J.J., Ly, A.V., 2006. Rasagiline: a second-generation monoamine oxidase type-B inhibitor for the treatment of Parkinson's disease. Am. J. Health Syst. Pharm. 63, 915-928.

Chen, J.J., Swope, D.M., Dashtipour, K., 2007. Comprehensive review of rasagiline, a second-generation monoamine oxidase inhibitor, for the treatment of Parkinson's disease. Clin. Ther. 29, 1825-1849.

Dimpfel, W., Hoffmann, J.A., 2011. Effects of rasagiline, its metabolite aminoindan and selegiline on glutamate receptor mediated signalling in the rat hippocampus slice in vitro. BMC Pharmacol. 11, 2.

Dunah, A.W., Standaert, D.G., 2001. Dopamine D1 receptor-dependent trafficking of striatal NMDA glutamate receptors to the postsynaptic membrane. J. Neurosci. 21, 5546-5558.

Gardoni, F., Schrama, L.H., Kamal, A., Gispen, W.H., Cattabeni, F., Di Luca, M., 2001 Hippocampal synaptic plasticity involves competition between $\mathrm{Ca} 2+/$ calmodulindependent protein kinase II and postsynaptic density 95 for binding to the NR2A subunit of the NMDA receptor. J. Neurosci. 21, 1501-1509.

Gardoni, F., Picconi, B., Ghiglieri, V., Polli, F., Bagetta, V., Bernardi, G., Cattabeni, F., Di Luca, M., Calabresi, P., 2006. A critical interaction between NR2B and MAGUK in L-DOPA induced dyskinesia. J. Neurosci. 26, 2914-2922.

Gardoni, F., Marcello, E., Di Luca, M., 2009. Postsynaptic density-membrane associated guanylate kinase proteins (PSD-MAGUKs) and their role in CNS disorders. Neuroscience $158,324-333$.

Kim, M.J., Dunah, A.W., Wang, Y.T., Sheng, M., 2005. Differential roles of NR2A- and NR2B-containing NMDA receptors in Ras-ERK signaling and AMPA receptor trafficking. Neuron 246, 745-760.

Lau, C.G., Zukin, R.S., 2007. NMDA receptor trafficking in synaptic plasticity and neuropsychiatric disorders. Nat. Rev. Neurosci. 8, 413-426.

Lees, A.J., Hardy, J., Revesz, T., 2009. Parkinson's disease. Lancet 373, 2055-2066.

Naoi, M., Maruyama, W., 2009. Functional mechanism of neuroprotection by inhibitors of type B monoamine oxidase in Parkinson's disease. Expert Rev. Neurother. 9, 1233-1250. 
Nash, J.E., Brotchie, J.M., 2002. Characterisation of striatal NMDA receptors involved in the generation of parkinsonian symptoms: intrastriatal microinjection studies in the 6-OHDA-lesioned rat. Mov. Disord. 17, 455-466.

Niittykoski, M., Haapalinna, A., Sirviö, J., 2003. Selegiline reduces N-methyl-D-aspartic acid induced perturbation of neurotransmission but it leaves NMDA receptor dependent long-term potentiation intact in the hippocampus. J. Neural Transm. $110,1225-1240$.

Olanow, C.W. Hauser, R.A Jankovic, J., Langston, W Lang A Poewe, W., Tolosa, E Stocchi, F., Melamed, E., Eyal, E., Rascol, O., 2008. A randomized, double-blind, placebo-controlled, delayed start study to assess rasagiline as a disease modifying therapy in Parkinson's disease (the ADAGIO study): rationale, design, and baseline characteristics. Mov. Disord. 23, 2194-2201.

Olanow, C.W., Rascol, O., Hauser, R., Feigin, P.D., Jankovic, J., Lang, A., Langston, W. Melamed, E., Poewe, W., Stocchi, F., Tolosa, E., ADAGIO Study Investigators, 2009. A double-blind, delayed-start trial of rasagiline in Parkinson's disease. N. Engl. J. Med. 361, 1268-1278.

Paillé, V., Picconi, B., Bagetta, V., Ghiglieri, V., Sgobio, C., Di Filippo, M., Viscomi, M.T. Giampà, C., Fusco, F.R., Gardoni, F., Bernardi, G., Greengard, P., Di Luca, M. Calabresi, P., 2010. Distinct levels of dopamine denervation differentially alter striatal synaptic plasticity and NMDA receptor subunit composition. J. Neurosci. 30, 14182-14193.

Picconi, B., Gardoni, F. Centonze, D., Mauceri, D. Cenci, M.A., Bernardi, G., Calabresi, P. Di Luca, M., 2004. Abnormal Ca2+-calmodulin-dependent protein kinase II function mediates synaptic and motor deficits in experimental parkinsonism. J. Neurosci. 24, 5283-5291.
Schapira, A.H., 2008. Mitochondria in the aetiology and pathogenesis of Parkinson's disease. Lancet Neurol. 7, 97-109.

Schotanus, S.M., Chergui, K., 2008. NR2A-containing NMDA receptors depress glutamatergic synaptic transmission and evoked-dopamine release in the mouse striatum. J. Neurochem. 106, 1758-1765.

Schotanus, S.M., Fredholm, B.B., Chergui, K., 2006. NMDA depresses glutamatergic synaptic transmission in the striatum through the activation of adenosine A1 receptors: evidence from knockout mice. Neuropharmacology 51, 272-282.

Verhagen Metman, L., 2002. Recognition and treatment of response fluctuations in Parkinson's disease: review article. Amino Acids 23, 141-145.

Weinreb, O., Amit, T. Bar-Am, O., Youdim, M.B., 2007. Induction of neurotrophic factors GDNF and BDNF associated with the mechanism of neurorescue action of rasagiline and ladostigil: new insights and implications for therapy. Ann. N. Y. Acad. Sci. 1122, 155-168.

Weinreb, O., Amit, T., Sagi, Y., Drigues, N., Youdim, M.B., 2009a. Genomic and proteomic study to survey the mechanism of action of the anti-Parkinson's disease drug, rasagiline compared with selegiline, in the rat midbrain. J. Neural Transm. 116, 1457-1472.

Weinreb, O., Mandel, S., Bar-Am, O., Yogev-Falach, M., Avramovich-Tirosh, Y., Amit, T. Youdim, M.B., 2009b. Multifunctional neuroprotective derivatives of rasagiline as anti-Alzheimer's disease drugs. Neurotherapeutics 6, 163-174.

Weinreb, O., Amit, T, Bar-Am, O. Youdim, M.B, 2010. Rasagiline, a novel antiParkinsonian monoamine oxidase-B inhibitor with neuroprotective activity. Prog. Neurobiol. 92, 330-344. 